\title{
Associations of LEP, CRH, ICAM-1, and LINE- 1 methylation, measured in saliva, with waist circumference, body mass index, and percent body fat in mid-childhood
}

Jocelyn Dunstan ${ }^{1 *}$, Joseph P. Bressler², Timothy H. Moran ${ }^{3}$, Jonathan S. Pollak², Annemarie G. Hirsch', Lisa Bailey-Davis ${ }^{4}$, Thomas A. Glass ${ }^{1}$ and Brian S. Schwartz ${ }^{2,4}$

\begin{abstract}
Background: Genetics explains a small proportion of variance in body mass index at the population level. Epigenetics, commonly measured by gene methylation, holds promise for understanding obesity risk factors and mechanisms.

Methods: Participants were 431 adolescents aged 10-15 years. BMI z-score, waist circumference z-score, and percent body fat were measured. Saliva samples were collected and methylation of promoter regions of four candidate genes or sequences (LEP, ICAM-1, CRH, and LINE-1) were measured in 3-4 CpG sites each. Linear regression was used to identify associations of methylation with obesity-related outcomes.

Results: After adjusting for age, in sex-stratified analysis, the three obesity-related outcomes were negatively associated with LEP methylation in obese boys only. There were no associations of methylation of the other genes or sequences and the obesity-related outcomes.

Conclusions: Our results are consistent with prior studies that reported sex differences in associations of obesity-related outcomes with LEP methylation, and also as would be expected in adipose tissue, the source of circulating leptin. The findings suggest that saliva might be an acceptable tissue for epigenetics studies in adolescents.
\end{abstract}

Keywords: Obesity, Epigenetics, DNA methylation, Sex differences, LEP, CRH, ICAM-1, LINE-1

\section{Background}

Childhood obesity is a major public health concern worldwide [1]. Obese children and adolescents may experience physical and psychological consequences, such as increased risk for the development of diabetes and cardiovascular diseases as well as low self-esteem [2]. Childhood obesity often persists into adulthood [3], with associated increased risk of premature mortality [4].

In the USA, the prevalence of obesity in 2013-2014 for children and adolescents between 6-11 and 12-19 years

\footnotetext{
* Correspondence: jdunsta1@jhu.edu

'Department of Epidemiology, Johns Hopkins Bloomberg School of Public Health, Baltimore, MD, USA

Full list of author information is available at the end of the article
}

of age was 19.6 and $20.6 \%$, respectively [5]. The prevalence differed by race/ethnicity, with evidence of highest prevalence in the Hispanic/Latino population $[5,6]$. Since genetic variation explains only a small proportion of the variation in BMI $[7,8]$, a growing number of studies have investigated the role of epigenetic factors. Gene expression is partially regulated by epigenetic mechanisms, which are changes that are not due to alterations of the DNA sequence [9]. Epigenetic mechanisms include DNA methylation, histone modification, and DNA-binding proteins [10].

Epigenetic changes in genes related to stress and appetite have been studied as predictors of satiety, appetite, and obesity [11]. In epidemiological studies, DNA methylation is the most frequent epigenetic mechanism studied 
because it can be measured in surrogate tissues in large populations in quantitative assays. The use of surrogate tissues requires evaluation like that presented herein. DNA methylation occurs primarily at cytosine within cytosine-guanine dinucleotides (CpG), and it affects gene expression by modifying the degree to which the DNA is accessible to promoters or suppressors [12].

This research evaluated associations between DNA methylation, measured in saliva samples, and anthropometric and body composition measurements (hereafter called "obesity-related measures") in 431 adolescents between 10 and 15 years of age. Associations were also examined in relation to medical information in electronic health records (EHR), dietary and physical activity behavioral questionnaires from the child, and parental BMI. We measured methylation in 3-4 CpG sites in the promoter regions of three candidate genes selected on the basis of different biological pathways that are involved in obesity: leptin ( $L E P$, associated with appetite and fat metabolism [13]), corticotropin-releasing hormone $(C R H$, stress and appetite [14]), and intracellular adhesion molecule (ICAM-1, inflammation [15]). In addition, methylation in the LINE-1 gene sequence was used to evaluate whether methylation in candidate genes evidenced specificity.

\section{Methods}

\section{Participants and design}

Subjects were identified, recruited, and enrolled during the summer months of 2013 and 2014. First, target communities were identified according to three criteria: (1) located within the Geisinger Clinic's 45-county catchment area; (2) had at least 75 primary care patients aged 10-15 years, the target age range for the study; and (3) it fell into one of the four cells of the community selection table, defined by having: (a) high or low proportions of overweight (BMI for age/sex percentile $\geq 85$ th) and obese (BMI for age/sex percentile $\geq 95$ th) children and (b) community environments considered obesogenic or obesoprotective based on community socioeconomic deprivation, population density, and physical activity diversity [16]. For the third criterion, environmental variables and community overweight/obesity prevalence were each first divided into quintiles along a gradient of obesogenic to obesoprotective environments and high to low overweight/obesity prevalence. Then, communities were selected in the first or fifth quintile for each in four strata: (1) obesogenic environment, high prevalence; (2)obesogenic environment, low prevalence; (3) obesoprotective environment, high prevalence; and (4) obesoprotective environment, low prevalence.
Children and adolescents (hereafter "children") were first identified using EHR to obtain age and address information. A pre-notification letter was next sent that provided the parent the option of opting out of the study. If this was not returned within 10 days, the household was next contacted by phone to enroll the child and one parent in the study. If the household agreed to participate, a home visit was scheduled. At each household visit, one parent/guardian and one child between 10 and 15 years of age were enrolled. A total of 431 dyads were enrolled from 28 communities that included 9 boroughs, 11 townships, and 8 census tracts ranging (median) from 7 to 28 (14.5) enrolled children per community.

Each household received a $\$ 30$ gift card for the time and effort. In 2013, 210 child-parent dyads were enrolled (22.2\% participation rate) and in 2014, 222 additional dyads participated (14.8\% participation rate). The most common reasons for lack of participation included passive refusal after 18 phone calls, active refusal after telephone contact, and incorrect telephone number [17]. The study was approved by the Institutional Review Boards at both the Geisinger Health System and the Johns Hopkins Bloomberg School of Public Health.

\section{Data collection}

During the in-home visit, trained research staff measured height using a portable stadiometer (model seca 213, seca North America, Inc.); weight and percent body fat (PBF, three times) with a calibrated portable digital scale with tetrapolar bioelectrical impedance analysis (model TBF-300A, TANITA Corporation of America, Inc., Arlington Heights, IL); and waist circumference (WC, three times) with a measuring tape. The measurements were taken following the NHANES anthropometric procedures manual [18]. Shoes and socks were removed prior to height and weight measurements, and children were asked to empty their pockets and remove heavy layers of clothing. The waist circumference was measured with one shirt layer and at the hip bone level. Participants were asked to cross their arms and place them at their opposite shoulders, and the measurement was taken during normal expiration.

Height and weight were used to estimate the body mass index (BMI, $\mathrm{kg} / \mathrm{m}^{2}$ ). Age- and sex-specific BMI zscores (hereafter BMI-z) were created based on national standards [19]. Similarly, measured WC mean values were used to create $\mathrm{WC} \mathrm{z}$-scores (WC-z) as previously reported [20]. Demographic information was obtained from a parent during the initial telephone contact. During the home visit, the child completed a selfadministrated questionnaire about food and physical activity environments and habits, as previously reported [17]. Data from EHR included use of Medical Assistance 
for health insurance (as a proxy measure of low family socioeconomic status (SES)), medication history (e.g., antibiotics, stimulants, antidepressants, and anti-anxiety agents), and selected diagnoses (e.g., asthma, diabetes, food allergies, other allergies, and mental health [ICD-9 codes 290.x to 319.x]). These were created as ever vs. never variables and evaluated in regression models one at a time.

\section{Epigenetic measures}

From each child, a saliva specimen was collected during the home visit using the Oragene-DISCOVER kit (OGR500, DNA Genotek, Inc, Ontario, Canada). DNA bisulfite conversion was accomplished using EZ DNA Methylation Kits (Zymo Research) by following the manufacturer's manual. Briefly, 0.5-1.0 $\mu \mathrm{g}$ of genomic DNA was first mixed with $5 \mu$ of M-Dilution Buffer and incubated at $37^{\circ} \mathrm{C}$ for $15 \mathrm{~min}$ and then mixed with $100 \mu \mathrm{l}$ of CT Conversion Reagent. Mixtures were incubated in a thermocycler with 16 thermal cycles at $95{ }^{\circ} \mathrm{C}$ for $30 \mathrm{~s}$ and $50{ }^{\circ} \mathrm{C}$ for $1 \mathrm{~h}$. Bisulfite-converted DNA samples were loaded onto 96-column plates provided in the kit for desulfonation and purification. The concentration of eluted DNA was measured using a NanoDrop 1000 spectrometer.

DNA methylation was quantitated using bisulfite-PCR and pyrosequencing using the following kits from Qiagen: ICAM1_02 for ICAM-1, CRH_01 for CRH, LEP_01 for LEP, and NOS3_02 for LINE-1. Sequencing was conducted using Pyromark Q24, and percent methylation was computed using the Pyromark Q24 Software v.2 in CpG mode. Details about the location of the measured $\mathrm{CpG}$ sites are in the online supporting information (Additional file 1: Table S1).

\section{Statistical analysis}

The primary goal of the analysis was to evaluate associations of obesity-related measures (BMI-z, WC-z, and $\mathrm{PBF}$ ) with DNA methylation at each $\mathrm{CpG}$ site and for the mean of that gene across sites while adjusting for potential confounding by age. Before performing the analysis, we considered the causal ordering of DNA methylation and obesity [21]. These are complex relationships that may involve bi-directional influences. However, we hypothesized that LINE-1, CRH, and $I C A M-1$ were predominantly antecedent contributors to weight gain. Thus, for these loci, we modeled obesity as the outcome with methylation as the predictor. In contrast, for $L E P$, because obesity is known to influence leptin levels and triggers leptin resistance [21], we modeled LEP methylation as the outcome with obesity as the predictor. Analysis was performed using Stata 14 (StataCorp LP, College Station, TX).

Summary statistics were first examined for all obesityrelated measures and for all DNA methylation by $\mathrm{CpG}$ site and as overall gene means, for all children combined, and then for boys and girls separately. Associations were evaluated using linear regression, first for all children combined, and then separately for boys and girls in a single model with a cross-product term between sex and the variable of interest. The model was adjusted for the child's age (centered) and evaluated non-linearity by inclusion of a quadratic term for age. Linear regression beta coefficients, standard errors, and $p$ values are reported.

Variables were also created from the child questionnaire, previously described [17] and evaluated in association with DNA methylation (three genes and one gene sequence) or obesity-related outcomes (as confounders of the relation with $L E P$ methylation). The questions were about home environment and the child's dietary and physical activity behaviors. Several questionnaire items were combined to create summary scores [22], as continuous variables if distributions were not highly skewed, or using tertiles if they were. Variables were only retained in the model if they had an associated $p$ value $<0.05$ when included in the model and if the beta coefficient for the primary predictor variable changed by more than $10 \%$ when the new variable was included. BMI was modeled as a continuous variable and also as indicator variables for overweight (BMI-z between 85th and 95th percentile) and obesity (BMI-z over the 95th percentile).

Reported results are not corrected for multiple comparisons. Normality of residuals, homoscedasticity, independence (collinearity), and sensitivity to outliers were evaluated in the final model by examination of variance inflation factors and added variable plots. A $p$ value $<0.05$ was considered statistically significant.

\section{Results}

\section{Description of the study subjects}

Of the 431 children included in the study, 210 were boys and 221 were girls. Their mean age was just under 13 years for boys and girls, 93\% were Caucasian, 35\% received Medical Assistance for health insurance, and sizable portions were overweight or obese (Table 1). The large majority of participating parents were mothers with mean BMI values approaching $30 \mathrm{~kg} / \mathrm{m}^{2}$.

Methylation levels at all $\mathrm{CpG}$ sites measured in the $C R H$ and ICAM-1 genes were low in both boys and girls with minimal variation (online supporting information, Additional file 2: Table S2). Mean methylation levels in LINE-1 were high for both boys and girls, and there were no differences by sex or obesity status. Methylation levels of $L E P$ differed by CpG site; there were also significant differences between boys and girls (Additional file 2: Table S2). 
Table 1 Summary statistics of participating children and parents

\begin{tabular}{|c|c|c|c|}
\hline & All & Males & Females \\
\hline \multicolumn{4}{|l|}{ Children } \\
\hline$N(\%)$ & $431(100)$ & $210(48.72)$ & $221(51.28)$ \\
\hline Mean age, years (SD) & $12.86(1.70)$ & $12.77(1.64)$ & $12.93(1.75)$ \\
\hline \multicolumn{4}{|l|}{ Race/ethnicity } \\
\hline Caucasian (\%) & 395 (92.72) & $187(90.78)$ & $208(94.55)$ \\
\hline Non-Caucasian (\%) & $31(7.28)$ & $19(9.22)$ & $12(5.45)$ \\
\hline \multicolumn{4}{|l|}{ Body mass index, $\mathrm{kg} / \mathrm{m}^{2}$} \\
\hline$<85$ th percentile (\%) & $285(65.67)$ & $135(64.29)$ & $150(66.96)$ \\
\hline 85th to 95th percentile (\%) & $71(16.36)$ & $32(15.24)$ & $39(17.41)$ \\
\hline 295th percentile (\%) & $78(17.97)$ & $43(20.48)$ & $35(15.62)$ \\
\hline Waist circumference z-score (\%) & $0.48(0.92)$ & $0.55(0.95)$ & $0.41(0.89)$ \\
\hline Percent body fat (SD) ${ }^{a}$ & $22.96(11.31)$ & $19.73(11.18)$ & $26.01(10.57$ \\
\hline Received medical assistance (\%) & $154(35.48)$ & $82(39.05)$ & $72(32.14)$ \\
\hline \multicolumn{4}{|l|}{ Parents } \\
\hline$N(\%)$ & $416(100)$ & $60(14.42)$ & $356(85.58)$ \\
\hline Mean age, years (SD) & $42.62(8.22)$ & $47.30(8.40)$ & $41.83(7.93)$ \\
\hline Body mass index, $\mathrm{kg} / \mathrm{m}^{2}$ (SD) & $29.17(7.48)$ & $29.73(5.78)$ & $29.08(7.73)$ \\
\hline
\end{tabular}

This table shows characteristics of our sample stratified by sex

${ }^{\text {a }}$ Percent body fat was available for only 430 children

\section{Associations of obesity-related measures and LEP methylation}

Obesity was consistently and strongly associated with LEP methylation and that association varied by sex (Table 2 and Fig. 1). Parental BMI was associated with both LEP methylation and obesity-related outcomes and changed the primary association more than $10 \%$; therefore, it was retained in all subsequent models. In contrast, inclusion of EHR or child questionnaire-derived variables in the models did not identify any as significant predictors of $L E P$ methylation. These variables also did not change relations of any obesity-related measure with LEP methylation.
The associations in the regression models were primarily driven by obese boys (Fig. 1). This was confirmed when the regression models were repeated in boys only, with indicators for overweight and obesity as the primary predictors (Table 3 ). The beta coefficients for obesity were negative and relatively large, indicating that obesity in boys was associated with lower LEP methylation levels.

\section{Associations of CRH, ICAM-1, and LINE-1 methylation with obesity-related outcomes}

Linear regression was next used to evaluate associations of methylation levels in $C R H, I C A M-1$, and LINE-1 in

Table 2 Stratified analysis (boys and girls) of adjusted associations for leptin methylation at four CpG sites and for overall mean as outcome and the three obesity-related measures as primary predictors

\begin{tabular}{|c|c|c|c|c|c|c|c|c|c|c|c|c|c|c|c|}
\hline \multirow[t]{3}{*}{ Predictor } & \multicolumn{15}{|c|}{ LEP methylation (dependent variable) } \\
\hline & \multicolumn{3}{|c|}{$\mathrm{CpG-1}$} & \multicolumn{3}{|l|}{ CpG-2 } & \multicolumn{3}{|l|}{ CpG-3 } & \multicolumn{3}{|l|}{ CpG-4 } & \multicolumn{3}{|l|}{ Mean } \\
\hline & $\begin{array}{l}\text { Boys } \\
\beta \text { (SE) }\end{array}$ & $\begin{array}{l}\text { Girls } \\
\beta \text { (SE) }\end{array}$ & $p^{\S}$ & $\begin{array}{l}\text { Boys } \\
\beta \text { (SE) }\end{array}$ & $\begin{array}{l}\text { Girls } \\
\beta \text { (SE) }\end{array}$ & $P$ & $\begin{array}{l}\text { Boys } \\
\beta \text { (SE) }\end{array}$ & $\begin{array}{l}\text { Girls } \\
\beta \text { (SE) }\end{array}$ & $P$ & $\begin{array}{l}\text { Boys } \\
\beta \text { (SE) }\end{array}$ & $\begin{array}{l}\text { Girls } \\
\beta \text { (SE) }\end{array}$ & $P$ & $\begin{array}{l}\text { Boys } \\
\beta \text { (SE) }\end{array}$ & $\begin{array}{l}\text { Girls } \\
\beta \text { (SE) }\end{array}$ & $P$ \\
\hline BMI-z & $\begin{array}{l}-0.765^{*} \\
(0.334)\end{array}$ & $\begin{array}{l}0.429 \\
(0.371)\end{array}$ & 0.02 & $\begin{array}{l}-0.341^{* *} \\
(0.146)\end{array}$ & $\begin{array}{l}0.001 \\
(0.162)\end{array}$ & 0.11 & $\begin{array}{l}-0.651^{* *} \\
(0.210)\end{array}$ & $\begin{array}{l}0.286 \\
0.234\end{array}$ & 0.003 & $\begin{array}{l}-1.058^{* *} \\
(0.364)\end{array}$ & $\begin{array}{l}0.190 \\
(0.405)\end{array}$ & 0.02 & $\begin{array}{l}-0.704^{* *} \\
(0.225)\end{array}$ & $\begin{array}{l}0.227 \\
(0.250)\end{array}$ & 0.01 \\
\hline WC-z & $\begin{array}{l}-1.064^{*} \\
(0.429)\end{array}$ & $\begin{array}{l}0.443 \\
(0.456)\end{array}$ & 0.01 & $\begin{array}{l}-0.515^{* *} \\
(0.187)\end{array}$ & $\begin{array}{l}-0.079 \\
(0.199)\end{array}$ & 0.10 & $\begin{array}{l}-0.681^{*} \\
(0.272)\end{array}$ & $\begin{array}{l}0.341 \\
(0.289)\end{array}$ & 0.01 & $\begin{array}{l}-1.235^{* *} \\
(0.469)\end{array}$ & $\begin{array}{l}0.273 \\
(0.498)\end{array}$ & 0.03 & $\begin{array}{l}-0.874^{* *} \\
(0.289)\end{array}$ & $\begin{array}{l}0.245 \\
(0.307)\end{array}$ & 0.01 \\
\hline PBF & $\begin{array}{l}-0.089^{*} \\
(0.036)\end{array}$ & $\begin{array}{l}0.057 \\
(0.039)\end{array}$ & 0.01 & $\begin{array}{l}-0.036^{*} \\
(0.016)\end{array}$ & $\begin{array}{l}0.005 \\
(0.017)\end{array}$ & 0.08 & $\begin{array}{l}-0.062^{* *} \\
(0.022)\end{array}$ & $\begin{array}{l}0.030 \\
(0.025)\end{array}$ & 0.01 & $\begin{array}{l}-0.102^{*} \\
(0.039)\end{array}$ & $\begin{array}{l}-0.009 \\
(0.044)\end{array}$ & 0.11 & $\begin{array}{l}-0.072^{* *} \\
(0.024)\end{array}$ & $\begin{array}{l}0.021 \\
(0.027)\end{array}$ & 0.01 \\
\hline
\end{tabular}

Ordinary least squares regression models were adjusted for age and parental BMI

$B M I-z$ body mass index $z$-score, WC- $z$ waist circumference $z$-score, $P B F$ percent body fat

$P$ values: ${ }^{* *} 0.001 \leq P<0.01 ;{ }^{*} 0.01 \leq P<0.05$

${ }^{\S} P$ value for interaction term between leptin methylation and sex 

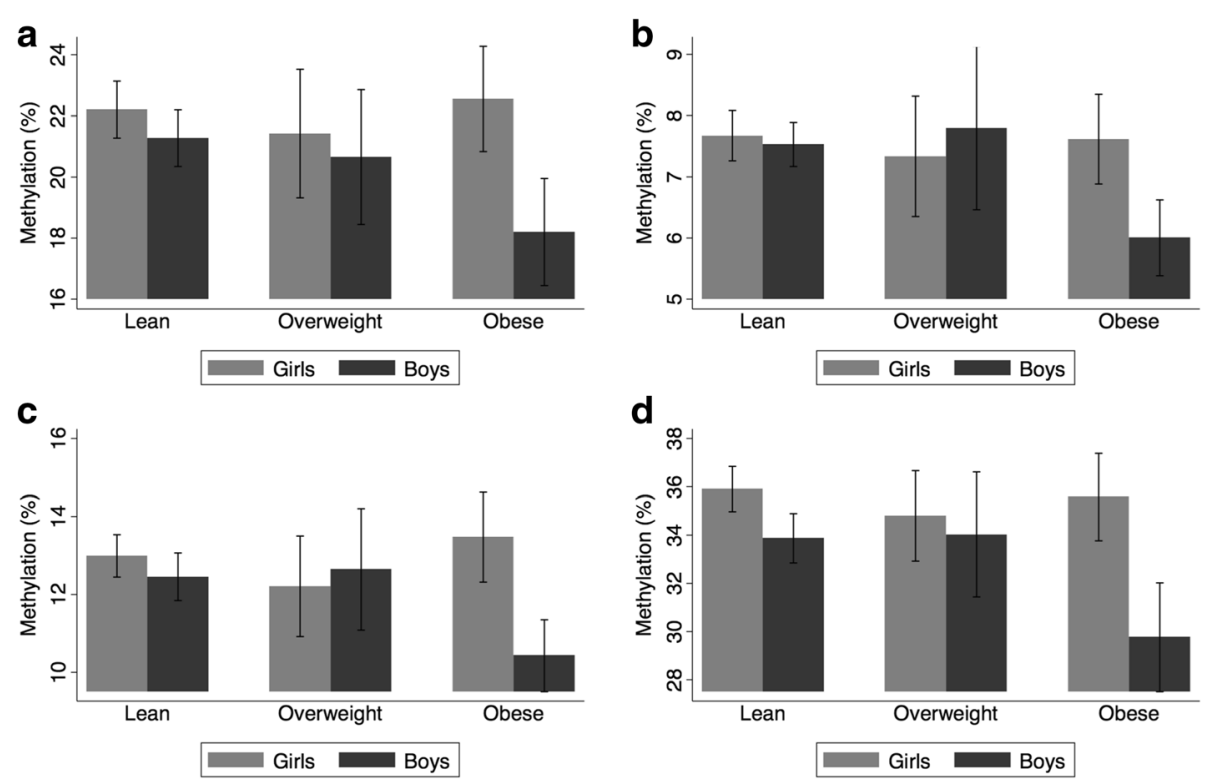

Fig. 1 LEP methylation in each CpG site, by sex, for lean, overweight, and obese children. a CpG-1, b CpG-2, c CpG-3, and d CpG-4

relation to the three obesity-related outcomes. There were no associations for $C R H$ or LINE-1 with any obesity-related measure for either boys or girls (results not shown). For ICAM-1, methylation of CpG1 was inversely associated with $\mathrm{PBF}$ in boys; mean methylation was inversely associated with WC-z in boys; and the cross product $p$ value between $\mathrm{CpG1}$ and sex was significant for all three obesity-related outcomes, with opposite directions of associations for boys and girls (online supporting information, Additional file 3: Table S3, Additional file 4). Inclusion of EHR variables (e.g., SES, child medication history, child diagnoses), child questionnaire-derived variables, and parental BMI in these models did not substantively change associations or inferences.

\section{Discussion}

This is the first large study to investigate associations between DNA methylation in candidate genes measured in saliva, related to appetite, stress, and inflammation, and obesity-related outcomes in children and adolescents. Three genes were chosen because they are important regulators of biological pathways involved in obesity: $C R H$ (stress), ICAM-1 (inflammation), and $L E P$ (appetite). A strong association was found between increased methylation in the $L E P$ promoter region in boys but not in girls. No associations were detected with methylation in the other genes, which had low absolute values with little variation, perhaps because of the $\mathrm{CpG}$ sites that were measured.

Several important confounding variables were evaluated, including child self-reported information on diet and physical activity, and medical history and medications from EHR data. None of these variables were associated with $L E P$ methylation levels. Analysis of EHR medication data was of interest, for example, because we have previously reported that stimulants were associated with BMI trajectories in children [23], and we were interested to evaluate whether this association may be mediated through LEP methylation, as both circulating leptin and stimulants affect appetite [7, 24].

Parental BMI was associated with both $L E P$ methylation and the obesity-related measures. There is consistent with prior evidence that parental BMI should be strongly associated with child BMI [3]. Most of the parents in the study were female (86\%), and some studies have looked at epigenetic changes passed by mothers

Table 3 Adjusted associations for LEP methylation in boys with overweight and obese status as primary predictor

\begin{tabular}{llllll}
\hline Obesity status & \multicolumn{1}{l}{ LEP methylation in boys (dependent variable) } & & & \\
\cline { 2 - 6 } & CpG-1 & CpG-2 & CpG-3 & CpG-4 & Mean \\
& $\beta(S E)$ & $\beta(S E)$ & $\beta(S E)$ & $\beta(S E)$ & $\beta(S E)$ \\
\hline Overweight & $0.373(1.140)$ & $0.730(0.495)$ & $0.850(0.719)$ & $1.207(1.243)$ & $0.790(0.768)$ \\
Obese & $-2.822^{* *}(0.993)$ & $-1.507^{* * *}(0.432)$ & $-2.149^{* * *}(0.627)$ & $-3.961^{* * *}(1.080)$ & $-2.610^{* * *}(0.666)$ \\
\hline
\end{tabular}

Models adjusted for age and parental BMl

$P$ values: ${ }^{* * *} P<0.001 ;{ }^{* *} 0.001 \leq P<0.01 ;{ }^{*} 0.01 \leq P<0.0$ 
to children, for example by measuring $L E P$ methylation in placental tissues [25]. We only had information about parental BMI at the date of the home visit, and no information about history of maternal hypoglycemia or gestational diabetes, which have been proposed as causal pathways to change DNA methylation [26].

$L E P$ is a polypeptide released from adipocytes that feeds back to neurons in the hypothalamus and other brain regions to suppress appetite. The regulation of $L E P$ is due, in part, to methylation at its prompter. Our finding that obese boys had lower levels of $L E P$ methylation would be expected to result in higher levels of leptin in serum and appetite suppression (but rodent models have provided some results inconsistent with this finding [27]). It should be noted that changes in LEP promoter methylation are not restricted to adipocytes; in addition to our study on saliva, similar findings have been reported using DNA from blood samples of children [13]. Another study reported a negative correlation between LEP methylation, measured in blood, and BMI in 73 persons with severe obesity, although no associations were found using subcutaneous or visceral adipose tissue [28]. This absence of specificity in adipocytes suggests that promoter methylation in the $L E P$ gene could be a potential biomarker for $L E P$ resistance from several cell types (possibly because those other cell types, such as leukocytes, are also involved in appetite regulation).

Sex differences in the methylation levels of $L E P$ have been reported previously. In a study conducted in infants (50 girls, 70 boys), higher BMI was negatively correlated with $L E P$ methylation in boys [29]. In the Dutch cohort of mothers who suffered famine during War Word II, famine exposure was associated with LEP methylation only in the male children compared to siblings of the same sex without famine exposure (the sample size was 311 children exposed and 311 control siblings) [30]. A possible explanation for the sex differences could be due to the involvement of leptin in sexual maturation. Leptin is an important hormone in female development [31]: similar to estrogens and progesterone, serum leptin levels change across the menstrual cycle [32]. Associations between $L E P$ promoter methylation and obesity in females may be difficult to discern because of the influence of sex hormones on DNA methyltransferases, the enzymes responsible for DNA methylation [33]. Prominent changes in hormone levels occur during puberty, which was likely to be occurring in many of our 10-15-year-old children.

One of the limitations of this study is that it was crosssectional, so temporal relations of epigenetic measures and obesity-related outcomes cannot be discerned. Another limitation is that only four genes or gene sequences were evaluated, in contrast to epigenome-wide approaches, which are the current standard in epigenetic research [34]. Budget limitations precluded epigenomewide measurements in our large sample. Finally, we did not have circulating leptin measurements, which would have been very helpful in assessing the biological plausibility of our findings.

\section{Conclusions}

We found an association between DNA methylation in each CpG site of the gene $L E P$, measure in saliva, and obesity-related measures in 431 children aged 1015 years old. This association differed by sex and obesity status, with a much stronger association in obese boys. No significant associations were observed in the $\mathrm{CpG}$ sites tested for ICAM-1, CRH and LINE-1. The results suggests that saliva may be a useful surrogate tissue for large-scale studies of epigenetics in relation to obesity, particularly in children and adolescents for whom venipuncture is an obstacle to study participation [35]. Saliva collection is non-invasive and inexpensive, and results were biologically consistent. Future studies should focus on the temporality of epigenetic changes in relation to the onset of obesity.

\section{Additional files}

Additional file 1: Table S1. Location of the CpG sites tested in the four candidate genes and gene sequence. (DOC $37 \mathrm{~kb}$ )

Additional file 2: Table S2. Percent methylation (mean \pm SD) in each CpG site, and the overall mean, of the four genes or gene sequences tested. (DOC $98 \mathrm{~kb}$ )

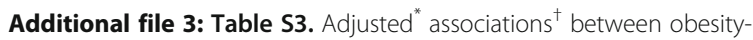
related measures (dependent variables) and ICAM-1 methylation (independent variable). (DOC $76 \mathrm{~kb}$ )

Additional file 4: Figure S1. Mean LEP methylation (mean of four CPG sites) plotted against the three obesity-related outcomes (BMl-z, WC-z, and PBF) for boys (blue circles) and girls (red triangles). The regression lines (fitted values) by sex are also shown in the plot. The extreme value in the body mass index $z$-score $(<-4)$ was confirmed and is not an erroneous value. (DOC $1239 \mathrm{~kb}$ )

\section{Abbreviations}

BMI-z: Body mass index z-score; EHR: Electronic health records; PBF: Percent body fat; WC-z: Waist circumference z-score

\section{Acknowledgements \\ We thank Joseph DeWalle for community mapping using ArcGIS and household selection; Sy Brandau, Kety Silva, and Saritha Korukonda for field data collection and home visits; and Dione Mercer for project management. DNA methylation was measured in the Genetic Resources Core Facility (GRCF) at Johns Hopkins School of Medicine.}

\section{Funding}

Research reported in this publication was supported by the Global Obesity Prevention Center (GOPC) at Johns Hopkins through the Eunice Kennedy Shriver National Institute of Child Health and Human Development (NICHD) and the Office of the Director (OD), National Institutes of Health, under award number U54HD070725. The content is solely the responsibility of the authors and does not necessarily represent the official views of the National Institutes of Health. 


\section{Availability of data and materials}

Data cannot be available because it is patient's health information. To establish formal collaboration, please contact Brian Schwartz at bschwar1@jhu.edu.

\section{Authors' contributions}

BSS, TAG, JB, AGH, and LB-D designed the study. BSS and AGH supervised the data collection. JD performed the statistical analysis, drafted the manuscript, and generated figures. BSS, THM, and TAG assisted with the interpretation of the results. All the authors did a critical revision of the manuscript. All authors read and approved the final manuscript.

\section{Competing interests}

The authors declare that they have no competing interests.

\section{Ethics approval and consent to participate}

The study was approved by the Institutional Review Boards at both the Geisinger Health System and the Johns Hopkins Bloomberg School of Public Health. We obtained parent's consent and child assent. Consent to publish was not necessary since this report does not contain individually identifiable information.

\section{Publisher's Note}

Springer Nature remains neutral with regard to jurisdictional claims in published maps and institutional affiliations.

\section{Author details}

'Department of Epidemiology, Johns Hopkins Bloomberg School of Public Health, Baltimore, MD, USA. ${ }^{2}$ Department of Environmental Health and Engineering, Johns Hopkins Bloomberg School of Public Health, Baltimore, MD, USA. ${ }^{3}$ Department of Psychiatry and Behavioral Sciences, Johns Hopkins School of Medicine, Baltimore, MD, USA. ${ }^{4}$ Department of Epidemiology and Health Services Research, Geisinger Health System, Danville, PA, USA.

\section{Received: 10 January 2017 Accepted: 18 March 2017}

Published online: 29 March 2017

\section{References}

1. Ebbeling CB, Pawlak DB, Ludwig DS. Childhood obesity: public-health crisis, common sense cure. Lancet. 2002;360:473-82.

2. Reilly JJ, Methven E, McDowell ZC, Hacking B, Alexander D, Stewart L, et al. Health consequences of obesity. Arch Dis Child. 2003;88:748-52.

3. Whitaker RC, Wright JA, Pepe MS, Seidel KD, Dietz WH. Predicting obesity in young adulthood from childhood and parental obesity. N Engl J Med. 1997;337:869-73.

4. Reilly JJ, Kelly J. Long-term impact of overweight and obesity in childhood and adolescence on morbidity and premature mortality in adulthood: systematic review. Int J Obes. 2011;35:891-8. doi:10.1038/ijo.2010.222.

5. Ogden CL, Carroll MD, Lawman HG, Fryar CD, Kruszon-Moran D, Kit BK, et al. Trends in obesity prevalence among children and adolescents in the United States, 1988-1994 through 2013-2014. Jama. 2016;315:2292. doi:10.1001/ jama.2016.6361

6. Mamtani M, Kulkarni H, Dyer TD, Göring HH, Neary JL, Cole SA, et al. Genomeand epigenome-wide association study of hypertriglyceridemic waist in Mexican American families. Clin Epigenetics. 2016;8:6. doi:10.1186/s13148-016-0173-x.

7. Xia Q, Grant SFA. The genetics of human obesity. Ann N Y Acad Sci. 2013; 1281:178-90.

8. van Dijk SJ, Tellam RL, Morrison JL, Muhlhausler BS, Molloy PL. Recent developments on the role of epigenetics in obesity and metabolic disease. Clin Epigenetics. 2015;7:66. doi:10.1186/s13148-015-0101-5.

9. Russo VEA, Martienssen RA, Riggs AD, others. Epigenetic mechanisms of gene regulation. Cold Spring Harbor Laboratory Press; 1996. https://scholar. google.co.uk/scholar?q=Epigenetic+mechanisms+of+gene+regulation.+ $\& b t n G=\& h l=e n \& a s \_s d t=0 \% 2 C 5$.

10. Waterland RA, Michels KB. Epigenetic epidemiology of the developmental origins hypothesis. Annu Rev Nutr. 2007;27:363-88. doi:10.1146/annurev. nutr.27.061406.093705.

11. Gardner KR, Sapienza C, Fisher JO. Genetic and epigenetic associations to obesity-related appetite phenotypes among African-American children. Pediatr Obes. 2015. doi: 10.1111/ijpo.12010.
12. Jaenisch $R$, Bird $A$. Epigenetic regulation of gene expression: how the genome integrates intrinsic and environmental signals. Nat Genet. 2003;33 Suppl march:245-54

13. García-Cardona MC, Huang F, García-Vivas JM, López-Camarillo C, Del Río Navarro BE, Navarro Olivos E, et al. DNA methylation of leptin and adiponectin promoters in children is reduced by the combined presence of obesity and insulin resistance. Int J Obes. 2014;38:1457-65. doi:10.1038/ijo.2014.30.

14. Fasting MH, Oken E, Mantzoros CS, Rich-Edwards JW, Majzoub JA, Kleinman $K$, et al. Maternal levels of corticotropin-releasing hormone during pregnancy in relation to adiponectin and leptin in early childhood. J Clin Endocrinol Metab. 2009;94:1409-15.

15. Eyzaguirre F, Mericq V. Insulin resistance markers in children. Horm Res. 2009:71:65-74.

16. Schwartz BS, Stewart WF, Godby S, Pollak J, DeWalle J, Larson S, et al. Body mass index and the built and social environments in children and adolescents using electronic health records. Am J Prev Med. 2011;41:e17-28.

17. Bailey-Davis L, Poulsen MN, Hirsch A, Pollak J, Glass TA, Schwartz BS. Home food rules in relation to youth eating behaviors, body mass index, waist circumference, and percent body fat. Pre-print. 1-23.

18. Centers for Disease Control and Prevention. National Health and Nutrition Examination Survey: Anthropometry Procedures Manual. 2007. http://www.cdc.gov/NCHS/data/nhanes/nhanes_07_08/manual_an.pdf. Accessed 11 Mar 2016

19. Centers for Disease Control and Prevention. 2000 CDC growth charts: United States. http://www.cdc.gov/growthcharts/cdc_charts.htm. Accessed 11 Mar 2016

20. Sharma AK, Metzger DL, Daymont C, Hadjiyannakis S, Rodd CJ. LMS tables for waist-circumference and waist-height ratio Z-scores in children aged 5-19y in NHANES III: association with cardio-metabolic risks. Pediatr Res. 2015;78:1-7.

21. Schwartz MW, Prigeon RL, Kahn SE, Nicolson M, Moore J, Morawiecki A et al. Evidence that plasma leptin and insulin levels are associated with body adiposity via different mechanisms. Diabetes Care. 1997;20:1476-81. doi:10.2337/diacare.20.9.1476

22. Rosenberg DE, Sallis JF, Kerr J, Maher J, Norman GJ, Durant N, et al. Brief scales to assess physical activity and sedentary equipment in the home. Int J Behav Nutr Phys Act. 2010;7:10. doi:10.1186/1479-5868-7-10.

23. Schwartz B S, Bailey-davis L, Bandeen-roche K, Pollak J, Hirsch AG, Nau C, et al. Attention Deficit Disorder, Stimulant Use, and Childhood Body Mass Index Trajectory. 2014:668-76.

24. Poulton AS, Hibbert EJ, Champion BL, Nanan RKH. Stimulants for the Control of Hedonic Appetite. Front Pharmacol. 2016:1-8. doi: 10.3389/ fphar.2016.00105.

25. Lesseur C, Armstrong DA, Paquette AG, Li Z, Padbury JF, Marsit CJ. Maternal obesity and gestational diabetes are associated with placental leptin DNA methylation. Am J Obstet Gynecol. 2014;211:654.e1-9. doi:10.1016/j.ajog. 2014.06.037.

26. Allard C, Desgagne V, Patenaude J, Lacroix M, Guillemette L, Battista M, et al. Mendelian randomization supports causality between maternal hyperglycemia and fetal metabolic programming by leptin epigenetic modulation. Circulation. 2015;131:342-51. doi:10.1080/15592294.2015.1029700.

27. Scarpace PJ, Matheny M, Tümer N, Cheng KY, Zhang Y. Leptin resistance exacerbates diet-induced obesity and is associated with diminished maximal leptin signalling capacity in rats. Diabetologia. 2005:48:1075-83.

28. Houde A-A, Légaré C, Biron S, Lescelleur O, Biertho L, Marceau S, et al. Leptin and adiponectin DNA methylation levels in adipose tissues and blood cells are associated with BMI, waist girth and $\mathrm{LDL}$-cholesterol levels in severely obese men and women. BMC Med Genet. 2015;16:29. doi:10.1186/s12881-015-0174-1.

29. Obermann-Borst SA, Eilers PH, Tobi EW, de Jong FH, Slagboom PE, Heijmans BT, et al. Duration of breastfeeding and gender are associated with methylation of the LEPTIN gene in very young children. Pediatr Res. 2013; 74:344-9. doi:10.1038/pr.2013.95

30. Tobi EW, Lumey LH, Talens RP, Kremer D, Putter H, Stein AD, et al. DNA methylation differences after exposure to prenatal famine are common and timing- and sex-specific. Hum Mol Genet. 2009;18:4046-53.

31. Elias CF, Purohit D. Leptin signaling and circuits in puberty and fertility. Cell Mol Life Sci. 2013;70:841-62.

32. Ahrens K, Mumford SL, Schliep KC, Kissell KA, Perkins NJ, WactawskiWende J, et al. Serum leptin levels and reproductive function during the menstrual cycle. Am J Obstet Gynecol. 2014;210:248.e1-9. doi:10. 1016/j.ajog.2013.11.009. 
33. Yamagata Y, Asada H, Tamura I, Lee L, Maekawa R, Taniguchi K, et al. DNA methyltransferase expression in the human endometrium: down-regulation by progesterone and estrogen. Hum Reprod. 2009;24:1126-32.

34. Wahl S, Drong A, Lehne B, Loh M, Scott WR, Kunze S, et al. Epigenome-wide association study of body mass index, and the adverse outcomes of adiposity. Nature. 2017;541:81.

35. Ozanne SE. Epigenetic signatures of obesity. N Engl J Med. 2015;372:973-4. doi:10.1056/NEJMcibr1414707.

Submit your next manuscript to BioMed Central and we will help you at every step:

- We accept pre-submission inquiries

- Our selector tool helps you to find the most relevant journal

- We provide round the clock customer support

- Convenient online submission

- Thorough peer review

- Inclusion in PubMed and all major indexing services

- Maximum visibility for your research

Submit your manuscript at www.biomedcentral.com/submit 